\title{
IMPLEMENTASI RUMUS SOBEL PADA WEB DENGAN TOPIK REGRESI LINIER MENGGUNAKAN VARIABEL INTERVENING
}

\section{Implementation Of Sobel Formulas On The Web With Linier Regression Using Intervening Variables}

\author{
Herlina, herlina@bundamulia.ac.id ${ }^{1}$, Thing Thing Diputra, \\ thingthingdiputra@gmail.com ${ }^{2)}$ \\ ${ }^{1) 2)}$ Teknik Informatika / Fakultas Teknologi dan Desain, Universitas Bunda Mulia
}

\begin{abstract}
Implementation of the sobel formula on the web is used to predict the indirect effect between independent and dependent variables. This web application, can be used to perform simple regression analysis as well as multiple linear regression. A simple linear regression consists of one independent variable $(x)$ and one dependent variable (y) that serves to find out how closely the relationship of two variables and know the contribution of the independent variable $(x)$ in explaining the dependent variable and can make predictions. Double linear regression consists of two or more independent vaiabel $(x)$ and one dependent variable (y). The data in this study can be either cross section or team series data. The purpose of implementation of sobel formula is to facilitate the researchers by utilizing the internet network that is connected on the web. The result of the implementation of the sobel formula is on the site https://thingdiputra.github.io/

Keywords: Linear regression, intervening variable, sobel formula
\end{abstract}

\begin{abstract}
ABSTRAK
Implementasi rumus sobel pada web digunakan untuk melakukan prediksi pengaruh tidak langsung antara variabel bebas dan terikat. Aplikasi berbasis web ini, dapat digunakan untuk melakukan analisis regresi sederhana maupun regresi linier ganda. Regresi linier sederhana terdiri dari satu variabel bebas (x) dan satu variabel terikat (y) yang berfungsi untuk mengetahui bagaimana keeratan hubungan dua variabel dan mengetahui kontribusi variabel bebas (x) dalam menjelaskan variabel terikat serta dapat melakukan prediksi. Regresi linier ganda terdiri dari dua atau lebih vaiabel bebas (x) dan satu variabel terikat (y). Data pada penelitian ini dapat berupa cross section atau data team series. Tujuan implementasi rumus sobel adalah mempermudah para peneliti dengan memanfaatkan jaringan internet yang dihubungkan pada web. Hasil implementasi rumus sobel terdapat di situs https://thingdiputra.github.io/

Kata kunci: Regresi linier, variabel intervening, rumus sobel
\end{abstract}

\section{PENDAHULUAN}

Perkembangan teknologi semakin pesat, berbagai aplikasi dapat di akses lewat mobile, tablet, laptop dan komputer dengan bantuan jaringan internet. Dalam melakukan analisis penelitian kuantitatif, biasanya menggunakan bantuan program statistik seperti SPSS, Amos, Lisrel dan lain-lain. Program-program tersebut umumnya menggunakan laptop dan PC. Untuk mempermudah peneliti, maka diperlukan melakukan implementasi rumus- rumus statistik pada web untuk mempermudah bagi khalayak umum dalam melakukan penelitian.

Implementasi rumus matematika pada topik regresi linier baik sederhana dan regresi ganda merupakan hal penting karena sebagian besar penelitian sosial tentang penelitian asosiasi atau hubungan sebab akibat. Selain hubungan sebab akibat, terdapat juga variabel intervening ataupun variabel moderat. Dimana variabel-variabel tersebut digunakan untuk mengetahui 
pengaruh tidak langsung antara varabel bebas dan variabel terikat.

Oleh karena itu, penelitian ini yaitu melakukan implementasi rumus sobel pada web pada topik regresi linier dengan variabel intervening. Dengan menggunakan implementasi ini, peneliti dapat dengan mudah menggunakan aplikasi berbasis web ini dimanapun dan kapanpun serta menggunakan media apapun dengan bantuan jaringan internet.

\section{METODE PENELITIAN}

\section{Jenis penelitian}

Penelitian ini merupakan jenis penelitian pengembangan yaitu mengembangkan rumus matematika ke ranah teknologi seperti website atau situs. Rumus statistik dihubungkan dengan jaringan-jaringan halaman (hyperlink) yang bersifat statis.

\section{Analisis regresi dan korelasi linier}

Koefisien korelasi sederhana ditunjukkan pada rumus (1)

$$
\mathrm{r}=\frac{\mathrm{n} \sum \mathrm{XY}-\left(\sum \mathrm{X}\right)\left(\sum \mathrm{Y}\right)}{\sqrt{\left(\mathrm{n} \sum \mathrm{X}^{2}-\left(\sum \mathrm{X}\right)^{2}\right)\left(\mathrm{n} \sum \mathrm{Y}^{2}-\left(\sum \mathrm{Y}\right)^{2}\right)}}
$$

koefisien determinasi $=\mathrm{r}^{2}$

uji t dan uji F ditunjukkan pada rumus (3)

$$
\begin{aligned}
& \mathrm{t}_{\mathrm{obs}}=\frac{\mathrm{r} \sqrt{\mathrm{n}-2}}{\sqrt{1-\mathrm{r}^{2}}} \quad \text { dengart } \mathrm{tab}=\left\{\frac{\alpha}{2} ;(\mathrm{n}-2)\right\} \\
& \mathrm{F} o=\frac{\mathrm{RKR}}{\mathrm{RKG}} ; \quad \mathrm{F}_{\mathrm{tab}}=\alpha ;(\mathrm{k}-1)(\mathrm{n}-\mathrm{k})
\end{aligned}
$$

Persamaan regresi sederhana ditunjukkan pada rumus (5)

$$
\hat{\mathrm{Y}}=\mathrm{a}+\mathrm{bX}
$$

Dimana

$$
\mathrm{a}=\frac{\left(\sum \mathrm{Y}\right)\left(\sum \mathrm{X}^{2}\right)-\left(\sum \mathrm{X}\right)\left(\sum \mathrm{XY}\right)}{\mathrm{n} \sum \mathrm{X}^{2}-\left(\sum \mathrm{X}\right)^{2}}
$$

$$
\mathrm{b}=\frac{\mathrm{n}\left(\sum \mathrm{XY}\right)-\left(\sum \mathrm{X}\right)\left(\sum \mathrm{Y}\right)}{\mathrm{n} \sum \mathrm{X}^{2}-\left(\sum \mathrm{X}\right)^{2}}
$$

Persamaan regresi berganda ditunjukkan pada rumus (8)

$$
\hat{\mathrm{Y}}=\mathrm{a}+\mathrm{b}_{1} \mathrm{X}_{1}+\mathrm{b}_{2} \mathrm{X}_{2}
$$

disesuaikan menjadi

$$
\mathrm{a}=\overline{\mathrm{Y}}-\mathrm{b}_{1} \overline{\mathrm{X}}_{1}-\mathrm{b}_{2} \overline{\mathrm{X}}_{2}
$$

Dimana

$$
\begin{aligned}
& \mathrm{b}_{1}=\frac{\left(\sum \mathrm{x}_{2}^{2}\right)\left(\sum \mathrm{x}_{1} \mathrm{y}\right)-\left(\sum \mathrm{x}_{1} \mathrm{x}_{2}\right)\left(\sum \mathrm{x}_{2} \mathrm{y}\right)}{\left(\sum \mathrm{x}_{1}^{2}\right)\left(\sum \mathrm{x}_{2}^{2}\right)-\left(\sum \mathrm{x}_{1} \mathrm{x}_{2}\right)^{2}} \\
& \mathrm{~b}_{2}=\frac{\left(\sum \mathrm{x}_{1}^{2}\right)\left(\sum \mathrm{x}_{2} \mathrm{y}\right)-\left(\sum \mathrm{x}_{1} \mathrm{x}_{2}\right)\left(\sum \mathrm{x}_{1} \mathrm{y}\right)}{\left(\sum \mathrm{x}_{1}^{2}\right)\left(\sum \mathrm{x}_{2}^{2}\right)-\left(\sum \mathrm{x}_{1} \mathrm{x}_{2}\right)^{2}}
\end{aligned}
$$

Untuk mencari rumus (10), maka terlebih dahulu menggunakan rumus (11) berikut ini kemudian subtitusi ke rumus (10):

$$
\begin{aligned}
& \sum \mathrm{x}_{1}^{2}=\sum \mathrm{X}_{1}^{2}-\frac{\left(\sum \mathrm{X}_{1}\right)^{2}}{\mathrm{n}} \\
& \sum \mathrm{x}_{1} \mathrm{y}=\sum \mathrm{X}_{1} \mathrm{Y}-\frac{\left(\sum \mathrm{X}_{1}\right)\left(\sum \mathrm{Y}\right)}{\mathrm{n}} \\
& \sum \mathrm{x}_{1} \mathrm{x}_{2}=\sum \mathrm{X}_{1} \mathrm{X}_{2}-\frac{\left(\sum \mathrm{X}_{1}\right)\left(\sum \mathrm{X}_{2}\right)}{\mathrm{n}} \\
& \sum \mathrm{x}_{2}^{2}=\sum \mathrm{X}_{2}^{2}-\frac{\left(\sum \mathrm{X}_{2}\right)^{2}}{\mathrm{n}} \\
& \sum \mathrm{x}_{2} \mathrm{y}=\sum \mathrm{X}_{2} \mathrm{Y}-\frac{\left(\sum \mathrm{x}_{2}\right)\left(\sum \mathrm{Y}\right)}{\mathrm{n}}
\end{aligned}
$$

\section{Analisis Jalur dengan rumus Sobel}

Imam Gozali (2013: 247-249), analisis jalur merupakan perluasan dari anaalsis regresi berganda. Analisis jalur digunakan jika terdapat variabel mediasi. Dalam penelitian ini variabel mediasi adalah minat belajar statistik. Penelitian ini menggunakan teknik analisis jalur. Desain penelitian komparatif dapat di lihat pada Gambar 1 dan 2.

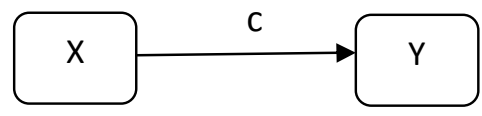




\section{Gambar 1 Hubungan Langsung $X$ Mempengaruhi Y}

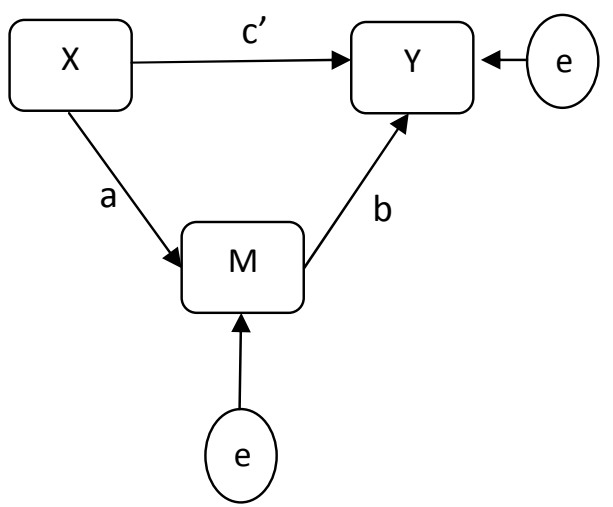

Gambar 2 Hubungan Tidak Langsung X Mempengaruhi Y Lewat M

Pada Gambar 1 variabel $\mathrm{X}$ berpengaruh langsung terhadap $\mathrm{Y}$ atau sering disebut direct effect, sedangkan Gambar 2 menggambarkan bentuk mediasi sederhana yaitu ada pengaruh tidak langsung $\mathrm{X}$ ke $\mathrm{Y}$, lewat $M$ sebagai variabel mediator. Hubungan sederhana antara X dan Y, lewat $M$ sebagai variabel mediator. Hubungan $X$ dan Y sering disebut total effect (Pengaruh Total) dengan nilai koefisien total c pada gambar 1. Koefisien $\mathrm{c}$ ini berbeda dengan koefisien c', koefisien c' merupakan koefisien pengaruh langsung (direct effect) $\mathrm{X}$ ke $\mathrm{Y}$ setelah mengendalikan M (Gambar 2).

Mendeteksi pengaruh mediasi secara langsung dengan melihat model gambar 2. Berdasarkan gambar 2 dapat ditulis persamaan regresi sebagai berikut:

$$
\begin{aligned}
& \hat{Y}=\alpha 1+c X \\
& \hat{Y}=\alpha 2+a X \\
& \hat{Y}=\alpha 3+c^{\prime} X+b M
\end{aligned}
$$

Variabel $M$ disebut mediator atau intervening jika persamaan (12) $\mathrm{X}$ secara signifikan mempengaruhi $\mathrm{Y}($ atau $\mathrm{c} \neq 0$ ), persamaan (13) $X$ secara signifikan mempengaruhi $M$ ( atau $a \neq 0$ ) dan persamaan (14) $X$ secara signifikan mempengaruhi $\mathrm{Y}$ dengan mengkontrol $\mathrm{X}(\mathrm{b}$ $\neq 0$ ). Jika pengaruh $\mathrm{X}$ terhdapa $\mathrm{Y}$ menurun menjadi nol dengan memasukan variabel M, maka terjadi mediasi sempurna. Namun demikian, jika pengaruh $\mathrm{X}$ terhadap $\mathrm{Y}$ menurun tidak sama dengan nol dengan memasukan variabel $\mathrm{M}$, maka terjadi mediasi parsial. Mediasi sederhana ini terjadi jika dipenuhi asumsi (12) tidak ada kesalahan pengukuran pada pada variabel $\mathrm{M}$, dan (13) variabel Y tidak mempengaruhi M.

Pengujian hipotesis mediasi dapat dilakukan dengan prosedur yang dikembangkan oleh sobel (1982) dan dikenal dengan uji sobel (Sobel Test). Uji sobel dilakukan dengan cara menguji kekuatan pengaruh pengaruh tidak langsung $\mathrm{X}$ ke $\mathrm{Y}$ lewat $\mathrm{M}$. Pengaruh tidak langsung $\mathrm{X}$ ke $\mathrm{Y}$ lewat $\mathrm{M}$ dihitung dengan cara mengalikan jalur $\mathrm{X}-\mathrm{M}$ (a) dengan jalur $\mathrm{M}-\mathrm{Y}$ (b) atau jalur ab. Jadi koefisien $\mathrm{ab}=($ c' - c), dimana $c$ adalah pengaruh $X$ terhadap Y tanpa mengontrol M, sedangkan c' adalah koefisien pengaruh $\mathrm{X}$ terhadap $\mathrm{Y}$ setelah mengontrol M. Standar error koefisien a dan $\mathrm{b}$ ditulis dengan $\mathrm{Sa}$ dan $\mathrm{Sb}$ dan besarnya standar error tidak langsung adalah Sab yang dihitung dengan rumus:

$$
S_{a b}=\sqrt{b^{2} s a^{2}+a^{2} s b^{2}+s a^{2} s b^{2}}
$$

Keterangan:

$\mathrm{Sa}=$ standar error koefisien a

$\mathrm{Sb}=$ standar error koefisien $\mathrm{b}$

$\mathrm{b}=$ koefisien variabel mediasi

$\mathrm{a}=$ koefisien variabel bebas

Untuk menguji signifikan pengaruh tidak langsung, maka kita perlu menghitung nilai $\mathrm{t}$ dari koefisien $\mathrm{ab}$ dengan rumus :

$$
\mathrm{t}=\frac{\mathrm{ab}}{\mathrm{S}_{\mathrm{ab}}}
$$

Nilai t hitung dibandingkan dengan nilai $t$ tabel. Jika nilai $\mathrm{t}$ hitung $>$ nilai $\mathrm{t}$ tabel maka disimpulkan terjadi pengaruh mediasi. Sobel test menghendaki asumsi jumlah sampel besar dan nilai koefisien mediasi berdistribusi normal. Tetapi asumsi ini telah banyak dikritik. Menurut Bollen dan Stine (1990) pada sampel kecil distribusinya umumnya tidak normal. Imam Gozali (2013: 248-255) 
Model Analisis jalur dalam penelitian ini sebegai berikut:

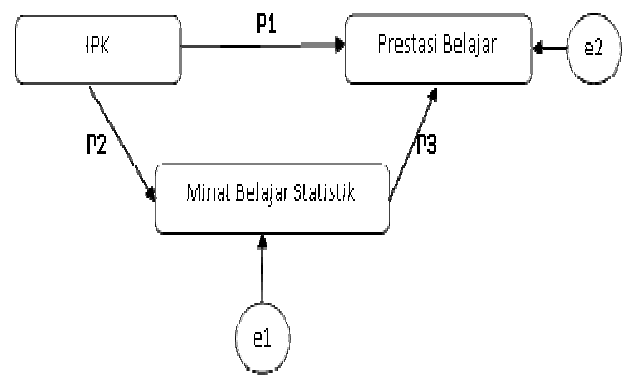

Gambar 3 Pengaruh IPK terhadap prestasi belajar dengan mediasi minat belajar statistik

Berdasarkan Gambar 3 dapat ditulis sebagai berikut:

Pengaruh langsung

IPK terhadap prestasi belajar $=\mathrm{P} 1$

Pengaruh tak langsung

IPK ke minat ke prestasi belajar $=\mathrm{P} 2 \times \mathrm{P} 3$

Total pengaruh $=\mathrm{P} 1+(\mathrm{P} 2 \times \mathrm{P} 3)$

$\mathrm{e} 1=\sqrt{\left(1-\mathrm{R}^{2}\right)}$ dan $\mathrm{e} 2=\sqrt{\left(1-\mathrm{R}^{2}\right)}$

Dimana

e1 merupakan variansi minat belajar statistik yang tidak dapat dijelaskan oleh IPK

e2 merupakan variansi prestasi belajar yang tidak dapat dijelaskan oleh IPK dan minat belajar statistik

Koefisien jalur dihitung dengan membuat dua persamaan struktural yaitu persamaan regresi yang menunjukan hubungan yang dihipotesiskan.

Dalam hal ini dua persamaan tersebut adalah:

Minat $=\alpha+\mathrm{P} 2 \mathrm{IPK}+\mathrm{e} 1$

Prestasi Belajar $=\alpha+$ P1 IPK + P3 Minat $+\mathrm{e} 2$

Uji sobel test

Standar error dari koefisien tidak langsung (Sp2p3)

$\mathrm{Sp} 2 \mathrm{p} 3=\sqrt{\mathrm{P} 3^{2} \mathrm{Sp} 2^{2}+\mathrm{P} 2^{2} \mathrm{Sp} 3^{2}+\mathrm{Sp} 2^{2} \mathrm{Sp} 3^{2}}$

Keterangan :
P2 dan P3 : koefisien

Sp2 dan Sp3 : standar error

Maka nilai $\mathrm{t}$ statistik pengaruh mediasi adalah

$\mathrm{t}=\frac{\mathrm{P} 2 \mathrm{P} 3}{\mathrm{Sp} 2 \mathrm{P} 3}$

\section{HASIL DAN PEMBAHASAN}

Untuk membantu hasil penelitian ini, dalam penelitian ini data yang digunakan merupakan data cross section. Untuk membantu implementasi rumus sobel, maka sebagai pelengkap yang digunakan untuk mengalikasikan rumus sobel menggunakan variabel bebas (x), variabel terikat (y), dan menggunakan variabel mediasi atau intervening (m). Berikut variabel bantuan dalam penelitian ini adalah:

$\mathrm{x}=$ IPK

$\mathrm{y}=$ Prestasi Belajar Statistik

$\mathrm{m}=$ Minat belajar Statistik

Hasil implementasi rumus sobel pada web

Variabel X terhadap Mediasi

Koefisien Korelasi ( $r): 0.170$

Koefisien Determinasi $(r 2): 0.029=$ $2.878 \%$

Tabel 1. Uji F pada $X$ terhadap Mediasi

\begin{tabular}{|c|c|c|c|c|c|}
\hline \multicolumn{6}{|c|}{$U j i F$} \\
\hline Sumber & $d f$ & $J K$ & $R K$ & Fhitung & Ftabel \\
\hline Regresi & 1 & 834.938 & 834.938 & 3.082 & 3.932 \\
\hline Sisa & 104 & 28.174.052 & 270.904 & & \\
\hline Total & 105 & 29.008 .991 & - & & \\
\hline
\end{tabular}

Kesimpulan : Model regresi secara signifikan tidak dapat digunakan untuk menganalisis data 
Tabel 2. Uji T pada $X$ terhadap Mediasi Uji T

\begin{tabular}{|c|c|c|c|c|}
\hline \multirow[t]{2}{*}{ Model } & \multicolumn{2}{|l|}{$\begin{array}{l}\text { Unstandardized } \\
\text { Coefficients }\end{array}$} & \multirow[t]{2}{*}{ thitung } & \multirow[t]{2}{*}{ ttabel } \\
\hline & $B$ & Std. Error & & \\
\hline Konstanta & 89.420 & 15.786 & 5.665 & 1.983 \\
\hline$X$ & 0.081 & 0.046 & 1.756 & \\
\hline
\end{tabular}

Kesimpulan :Koefisien konstanta secara signifikan berpengaruh terhadap Minat.Koefisien IPK secara signifikan tidak berpengaruh terhadap Minat

Variabel X \& Mediasi Terhadap $Y$

Koefisien Korelasi (r) : 0.619

Koefisien Determinasi $(r 2): 0.383=$ $38.335 \%$

Tabel 3.Uji F pada X dan Mediasi terhadap Y

\begin{tabular}{|c|c|c|c|c|c|}
\hline \multicolumn{6}{|c|}{$U j i F$} \\
\hline Sumber & $d f$ & $J K$ & $R K$ & Fhit & Ftab \\
\hline Regresi & 2 & 17.509 .885 & 8.754 .943 & 32.02 & 3.08 \\
\hline Sisa & 103 & 28.165 .964 & 273.456 & & \\
\hline Total & 105 & 45.675 .849 & - & & \\
\hline
\end{tabular}

Kesimpulan :Model regresi secara signifikan dapat digunakan untuk menganalisis data

Tabel 4.Uji $T$ pada $X$ dan Mediasi terhadap Y

\begin{tabular}{|c|c|c|c|c|}
\hline \multicolumn{5}{|c|}{$U j i T$} \\
\hline \multirow[t]{2}{*}{ Model } & \multicolumn{2}{|c|}{$\begin{array}{l}\text { Unstandardized } \\
\text { Coefficients }\end{array}$} & \multirow[t]{2}{*}{ thitung } & \multirow[t]{2}{*}{ ttabel } \\
\hline & $B$ & Std. Error & & \\
\hline Konstanta & -76.619 & 18.142 & -4.223 & \multirow[t]{3}{*}{1.983} \\
\hline$I P K$ & 0.296 & 0.047 & 6.310 & \\
\hline Minat & 0.372 & 0.099 & 3.779 & \\
\hline \multicolumn{5}{|c|}{$\begin{array}{l}\text { variabel bebas IPK; variabel mediasi Minat; variabel terikat } \\
\text { Prestasi }\end{array}$} \\
\hline \multicolumn{5}{|c|}{$\begin{array}{l}\text { Kesimpulan :Koefisien konstanta secara } \\
\text { signifikan tidak berpengaruh terhadap } \\
\text { Prestasi. Koefisien IPK secara signifikan } \\
\text { berpengaruh terhadap Prestasi. Koefisien }\end{array}$} \\
\hline
\end{tabular}

Minat secara signifikan berpengaruh terhadap Prestasi

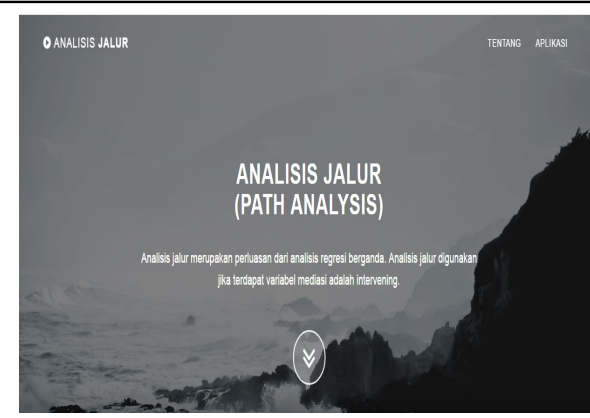

\section{Analisis Jalur (Path Analysis)}
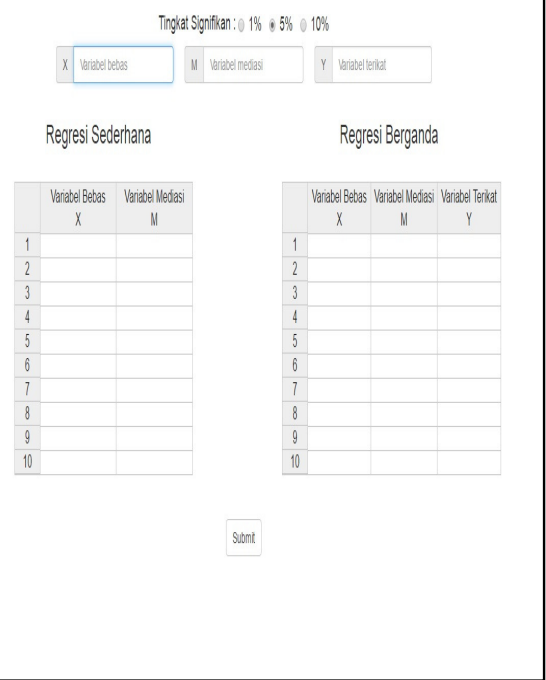

Gambar 4 Tampilan Web

Analisis Jalur

Persamaan Struktural

Minat $=0.081 \mathrm{IPK}+0.986$

Prestasi $=0.296 I P K+0.372$ Minat + 0.785

\begin{tabular}{|c|c|c|}
\hline \multicolumn{3}{|c|}{ Uji Sobel Test } \\
\hline $\begin{array}{c}\text { Standar Error } \\
\text { (Sp2p3) }\end{array}$ & thitung & ttabel \\
\hline 0.019 & 1.550 & 1.983 \\
\hline
\end{tabular}

Kesimpulan :Koefisien mediasi tidak memiliki pengaruh yang signifikan 


\section{SIMPULAN}

Berdasarkan hasil implementasi, penggunaan aplikasi rumus sobel pada web memiliki hasil yang sama dengan SPSS. Berikut link implementasi rumus sobel pada regresi linier dengan menggunakan variabel intervening https://thingdiputra.github.io/

\section{DAFTAR PUSTAKA}

[1] Ghozali, Imam. 2014. Aplikasi Analisis Multivariate dengan Program IBM SPSS 21. Semarang: Badan Penerbit Universitas Diponegoro
[2] Herlina. 2016. Analisis Komparatif Prestasi Belajar Statistik Ditinjau Dari Minat Belajar Dan IPK. Penelitian Universitas Bunda Mulia.

[3] Levine David M, dkk. (2016). Business Statistics A First Course Seventh Edition. England: Pearson Education.

[4] Toni Kun. (2010). Membuat Website Canggih Dengan Jquery Untuk Pemula. MediaKita: Jakarta

[5] Ramadhan Arief. (2006). Student Guide Series: Pemrograman Web Database dengan PHP dan MySQL. Elek Media Komputindo: Jakarta 